\title{
Integrative study of hypothalamus-pituitary-thyroid-immune system interaction: thyroid hormone-mediated modulation of lymphocyte activity through the protein kinase $C$ signaling pathway
}

\author{
Alicia J Klecha ${ }^{1,2}$, Ana M Genaro ${ }^{1,2}$, Gabriela Gorelik ${ }^{1}$, \\ María Laura Barreiro Arcos, Dafne Magalí Silberman', \\ Mariano Schuman ${ }^{3}$, Silvia I Garcia ${ }^{3}$, Carlos Pirola ${ }^{3}$ \\ and Graciela A Cremaschi, ${ }^{1,2}$ \\ ${ }^{1}$ Centro de Estudios Farmacológicos y Botánicos (CEFYBO), CONICET, Facultad de Medicina, Universidad de Buenos Aires, Paraguay 2155 , piso 15, \\ Primera Cátedra de Farmacología, 1121 Buenos Aires, Argentina \\ ${ }^{2}$ Laboratorio de Radioisótopos, Facultad de Farmacia y Bioquímica, Universidad de Buenos Aires, Junin 956, 1113 Buenos Aires, Argentina \\ ${ }^{3}$ Instituto de Investigaciones Médicas Alfredo Lanari, Facultad de Medicina, Universidad de Buenos Aires, AV. Combatients de Malvinas 3105 , 1427 Buenos \\ Aires, Argentina \\ (Requests for offprints should be addressed to G A Cremaschi at CONICET, Facultad de Medicina; Email: grace@ffyb.uba.ar)
}

\begin{abstract}
Thyroid hormones play critical roles in differentiation, growth and metabolism, but their participation in immune system regulation has not been completely elucidated. Modulation of in vivo thyroid status was used to carry out an integrative analysis of the role of the hypothalamus-pituitary-thyroid (HPT) axis in T and B lymphocyte activity. The participation of the protein kinase $\mathrm{C}(\mathrm{PKC})$ signaling pathway and the release of some cytokines upon antigenic stimulation were analyzed. Lymphocytes from hyperthyroid mice displayed higher Tand B-cell mitogen-induced proliferation, and those from hypothyroid mice displayed lower T- and B-cell mitogeninduced proliferation, compared with euthyroid animals. Reversion of hypothyroid state by triiodothyronine (T3) administration recovered the proliferative responses. No differences were found in lymphoid subset balance. Both total PKC content and mitogen-induced PKC translocation were higher in $\mathrm{T}$ and $\mathrm{B}$ cells from hyperthyroid mice, and lower in cells from hypothyroid mice, compared with
\end{abstract}

controls. Levels of thyroid-stimulating (TSH) and TSHreleasing $(\mathrm{TRH})$ hormones were not directly related to lymphocyte proliferative responses. After immunization with sheep red blood cells (SRBCs) and re-stimulation, in vitro spleen cells from hyper- or hypothyroid mice showed, respectively, increased or decreased production of interleukin (IL) -2 and interferon (IFN) $\gamma$ cytokines. Additionally, an increase in IL-6 and IFN- $\gamma$ levels was found in hyperthyroid cells after in vivo injection and in vitro re-stimulation with lipopolysaccharide (LPS).

Our results show for the first time a thyroid hormonemediated regulation of PKC content and of cytokine production in lymphocytes; this regulation could be involved in the altered responsiveness to mitogen-induced proliferation of $\mathrm{T}$ and $\mathrm{B}$ cells. The results also confirm the important role that these hormones play in regulating lymphocyte reactivity.

Journal of Endocrinology (2006) 189, 45-55

\section{Introduction}

Homeostatic regulation of immunity involves factors that are traditionally considered outside the immune system, including hormones and neurotransmitters. Thyroid hormones play critical roles in differentiation, growth and metabolism (Yen 2001). Although thyroid hormone participation in primary and secondary lymphopoiesis has been described (for review see Fabris et al. (1995), in general their effects on the immune system have received comparatively less attention than those from hormones of the hypothalamus-pituitary-adrenal axis (Dorshkind \&
Horseman 2000, Wang \& Klein 2001). This fact could be related to the dominating role of autoimmunity in the pathogenesis of thyroid disorders (Pawlikowski et al. 1994).

Interactions between pituitary-thyroid hormones and the immune system are mainly based on the existence of receptors for thyreotropic and thyroid hormones on lymphocytes or on the frequent immune alterations observed in physiological and pathological fluctuations of thyroid hormones. Hypothyroidism in humans, or experimentally induced hypothyroidism (propylthiouracil (PTU) treatment) and thyroidectomy in rodents, has been shown 
to diminish thymic activity, effects that were reversed by treatment with thyroid hormones (Fabris et al. 1995). In addition, hypothyroid experimental conditions lead to spleen and lymph node involution, as well as to depressed humoral and cell-mediated immune responses (Chatterjee \& Chandel 1983, Ohashi \& Itoh 1994, Klecha et al. 2000). Restoration of thyroid function, after thiourea-induced blockade, restored the humoral response to sheep red blood cells (SRBCs) in birds (Keast \& Ayre 1980). Moreover, suppression of cell-mediated immunity in severe human hypothyroidism, with improvement of lymphocyte function during a gradual return to the euthyroid state, has also been described (Schoenfeld et al. 1995).

Conversely, contradictory results exist in the literature on the effect of experimental hyperthyroidism on the humoral and cellular immunity. Thus, either an enhancing or suppressing effect of primary antibody responses (Fabris et al. 1995, Klecha et al. 2000) or of T and B lymphocyte proliferation (Chatterjee \& Chandel 1983, Klecha et al. 2000) was demonstrated in hyperthyroid conditions. Opposing data could be reflecting differences among species or among the hormonal treatment established. In fact an integrative study of the hypothalamuspituitary-thyroid (HPT) axis function has not previously been performed.

Recent evidence arising from analysis of lymphocyte development and function in mice with genetic defects in the expression of thyroid hormones or their receptors suggested that these hormones are not obligatory for the development of a normal immune response. Instead, the hypothesis proposed was that they are involved in maintaining immune system homeostasis in response to environmental changes or stress-mediated immunosuppression (Davis 1998, Dorshkind \& Horseman 2000, 2001). In fact, no alteration in humoral or cell-mediated immunity was found in dwarf mice with genetic defects in genes encoding for several anabolic hormones (including thyroid hormones) or in thyroid hormone-deficient hyt/hyt knockout mice (Foster et al. 2000). Although knockout mice studies have demonstrated that hormone deficiency is not incompatible with life, many of the effects on peripheral tissues were milder in these animals than those seen in congenital hypothyroidism (Yen 2001).

On this basis, the aim of this work was to perform an integrative analysis of the role of HPTstatus on T and B lymphocyte activation through the in vivo modulation of thyroid status. In addition, we aimed to study for the first time the participation of protein kinase $\mathrm{C}$ (PKC) intracellular signaling in thyroid hormone modulation of lymphocyte proliferation and to examine key cytokine levels induced by antigen challenge. Here we show a thyroidal state-mediated regulation of mitogen-induced lymphocyte proliferation related to the total cellular and membrane-associated content of PKC and of cytokines involved in lymphocyte activation during biologically relevant situations.

\section{Materials and Methods}

\section{Mice}

Inbred BALB/c $\left(\mathrm{H}-2^{\mathrm{d}}\right)$ female mice were obtained from the Instituto de Tecnología Agropecuaria de la República Argentina (INTA). All animals used were 60-70 days old and were handled according to the International Regulations for the Care and Use of Laboratory Animals.

In vivo thyroid hormones and anti-thyroid agent treatments

In order to induce high levels of thyroid hormones, mice were treated with thyroxine (T4) as it is usually used in normal replacement therapies in hypothyroid patients due to its higher half-life compared with triiodothyronine (T3). For this reason T4 displays a constant potency and prolonged action through its conversion to T3 in peripheral tissues. The treatment was performed according to previously described procedures (Shinohara et al. 2000). Briefly, BALB/c mice received a subcutaneous injection of $0.6 \mu \mathrm{g} / \mathrm{g}$ body weight (BW) T4 (Sigma) (dissolved in

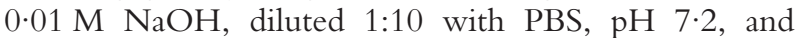
Millipore filtered) every day for 30 days. In this way almost undetectable values of thyroid-stimulating hormone (TSH) were obtained. Mice injected with the vehicle alone were used as controls.

The anti-thyroid drug PTU was chosen for hypothyroidism development for two reasons. First, anti-thyroid drugs are usually used in human hyperthyroidism treatment (Streetman \& Khanderia 2003). Secondly, more drastic treatments, such as surgical or ${ }^{131}$ I-induced thyroidectomy, also affect immune function (Ohashi \& Itoh 1994), with the latter also being genotoxic for lymphocytes (Ballardin et al. 2002). To promote low circulating levels of thyroid hormones in BALB/c mice, PTU was given in the drinking water $(0.5 \mathrm{mg} / \mathrm{ml})$ for 18 days as previously described (Klecha et al. 2000). The dailyingested amount of PTU was approximately $60 \mu \mathrm{g} / \mathrm{g} \mathrm{BW}$ per day.

Reversion of PTU treatment was achieved via T3 administration since this anti-thyroid drug also blocks peripheral conversion of T4 to T3. For PTU+T3 treatment, animals treated with PTU also received $0 \cdot 2 \mu \mathrm{g} / \mathrm{g}$ BW per day of T3 (dissolved in the same vehicle as used for thyroxine) for the last 6 days of treatment. Control animals received the vehicle alone.

\section{Cell suspensions and culture conditions}

Lymphoid cell suspensions from euthyroid, hyperthyroid, hypothyroid or PTU+T3-treated animals' lymph nodes, spleen or nylon wool purified $\mathrm{T}$ cells, were prepared asceptically as described previously (Cazaux et al. 1995). Cells were cultured at a concentration of $1 \times 10^{6}$ cells $/ \mathrm{ml}$, in RPMI 1640 medium (Gibco) supplemented with 10\% 
heat-inactivated fetal calf serum (FCS), $2 \mathrm{mM}$ glutamine and antibiotics - alone or in the presence of optimal mitogenic concentrations of selective $\mathrm{T}$ cell-mitogen, concanavalin A (Con A, $2 \mu \mathrm{g} / \mathrm{ml}$ ) or B cell-mitogen lipopolysacharide (LPS, $25 \mu \mathrm{g} / \mathrm{ml}$ ). Both mitogens were from Sigma. All cultures were incubated for the indicated times, as microcultures settled at a final volume of $0.2 \mathrm{ml}$ in 96-well flat-bottom microtiter plates or as macrocultures in T-25 culture flasks (Corning, NY, USA).

\section{Proliferation assays}

Proliferation was evaluated by pulses of $\left[{ }^{3} \mathrm{H}\right]$ thymidine $\left(\left[{ }^{3} \mathrm{H}\right] \mathrm{TdR}, 25 \mathrm{Ci} / \mathrm{mmol}\right.$; New England Nuclear, Perkin Elmer Inc, Boston, MA, USA) $16 \mathrm{~h}$ before the end of the culture incubation in both microcultures and $0.2 \mathrm{ml}$ aliquots from the macrocultures, as described previously (Cazaux et al. 1995). Results were expressed as d.p.m. values in experimental cultures minus the d.p.m. control values obtained in cultures of unstimulated cells. When indicated, PKC blockers were added at the beginning of cultures and $40 \mathrm{~min}$ prior to mitogen addition. It is worth noting that inhibitors alone do not significantly modify unstimulated lymphocyte cultures or affect cell viability at the indicated doses.

\section{Lymphocyte subset determination by flow cytometry}

CD4 T-helper/inducer and CD8 T-cytotoxic/suppressor lymphocytes were determined in lymph nodes or spleen cell suspensions by flow cytometry. Briefly, aliquots of cell suspensions $\left(1 \times 10^{6}\right)$ were stained with both fluoresceinconjugated anti-mouse CD4 (CD4-FITC) or with R-phycoerythrin-conjugated anti-mouse CD8 (CD8-PE) monoclonal antibodies. Lymphocytes were identified by FACS analysis using a FACScan flow cytometer (Becton Dickinson, Franklin Lakes, NJ, USA) with log amplification and FACScan research software. Optimal amounts of antibodies were used and 8000-10000 events were analysed per tube. Dot plots of two color fluorescence analysis as well as percentages of lymphocytes expressing $\mathrm{CD} 4$ and CD8 were determined. Isotype controls (IgG1FITC/IgG2a-PE) were used for each assay to determine non-specific staining.

\section{HPT axis evaluation}

Serum levels of T3 and T4 were determined with commercial RIA kits (Diagnostic Products Corporation, Los Angeles, CA, USA) according to manufacturer's instructions. TSH serum levels were determined by a RIA methodology developed in our laboratory using antimurine TSH (AFP98991) antibody, rat TSH for iodination (rTSH-I-9) and mouse TSH reference preparation (AFP98991) as standards (reagents kindly provided by Dr A F Parlow from the National Hormone and Peptide
Program, Bethesda, MD, USA). Hypothalamic TSHreleasing hormone $(\mathrm{TRH})$ was determined by RIA as described elsewhere (García et al. 1992). Briefly, animals were killed by decapitation and brains were rapidly removed. The diencephalic region of each animal was rapidly dissected with the aid of a stereotaxic atlas. In order to avoid the degradation of authentic TRH and the formation of TRH-like substances, samples (one diencephalum) were boiled in $2 \mathrm{M}$ acetic acid-100 $\mathrm{mM}$ $\mathrm{HCl}$ for $20 \mathrm{~min}$, homogenized and centrifuged at $10000 \mathrm{~g}$ for $10 \mathrm{~min}$. The supernatants were lyophilized and residues dissolved in RIA buffer. The polyclonal anti-TRH antibody was raised in New Zealand White rabbits immunized with TRH coupled to BSA using the bis-diazotized benzidine reaction. Standards or samples were incubated with $\left[{ }^{125} \mathrm{I}\right]$-labeled TRH and anti-TRH antibody $(1 / 10000)$ at $4{ }^{\circ} \mathrm{C}$ overnight. Bound hormone was pelleted with rabbit normal serum and a second antibody against rabbit IgG. All samples were assayed in duplicate. The minimum detectable amount was 5-10 pg. Intra- and inter-assay coefficients of variation were less than $7 \cdot 0$ and $14 \cdot 0 \%$ respectively.

\section{PKC determination}

$\mathrm{T}$ or B lymphocytes from normal, hypothyroid or hyperthyroid mice were incubated alone or in the presence of Con A $(2 \mu \mathrm{g} / \mathrm{ml})$ or LPS $(25 \mu \mathrm{g} / \mathrm{ml})$ for $10 \mathrm{~min}$ and were immediately frozen at a concentration of $1 \times 10^{7}$ cells/ sample in liquid $\mathrm{N}_{2}$. PKC was purified from subcellular fractions as previously described (Gorelik et al. 2002). PKC activity was assayed by measuring the incorporation of ${ }^{32} \mathrm{P}$ from $\left[\gamma_{-}{ }^{32} \mathrm{P}\right]$-ATP into histone $\mathrm{H}_{1}$. Incubations were conducted in a final volume of $85 \mu \mathrm{l}$ at $30^{\circ} \mathrm{C}$ for $30 \mathrm{~min}$. In the final concentrations, the assay mixture contained $25 \mathrm{mM}$ ATP $(0.4 \mathrm{mCi}), 10 \mathrm{mM}$ magnesium acetate, $5 \mathrm{mM} \beta$-mercaptoethanol, $50 \mathrm{mg}$ histone $\mathrm{H}_{1}$, $20 \mathrm{mM}$ HEPES, $\mathrm{pH} 7 \cdot 5$, and, unless otherwise indicated, $0.2 \mathrm{mM} \mathrm{CaCl}$ and $10 \mathrm{mg} / \mathrm{ml}$ of phosphatidylserine vesicles. The incorporation of $\left[{ }^{32} \mathrm{P}\right]$ phosphate into histone was linear for at least $30 \mathrm{~min}$. The reaction was stopped by the addition of $2 \mathrm{ml}$ ice-cold $5 \%$ trichloroacetic acid with $10 \mathrm{mM} \mathrm{H}_{3} \mathrm{PO}_{4}$. The radioactivity retained on GF/C glass fiber filters after filtration was determined by counting the filters in $2 \mathrm{ml}$ scintillation fluid. PKC activity was determined after subtracting the ${ }^{32} \mathrm{P}$ incorporation in the absence of $\mathrm{Ca}^{2+}$ and phospholipids. Data were expressed as picomoles of phosphate incorporated into the substrate per minute and per $10^{7} \mathrm{cells}$ ( $\mathrm{pmol} / \mathrm{min}$ per $10^{7}$ cells). Alternatively, the PKC enzyme assay system kit (Amersham) was also used to measure the PKC activity of subcellular lymphoid fractions, according to the manufacturer's instructions. Where indicated the content of PKC in samples was calculated by interpolating the phosphorylation rate ( $\mathrm{pmol} / \mathrm{min}$ ) of the samples in a doseresponse curve obtained with PKC purified from rat brain. 

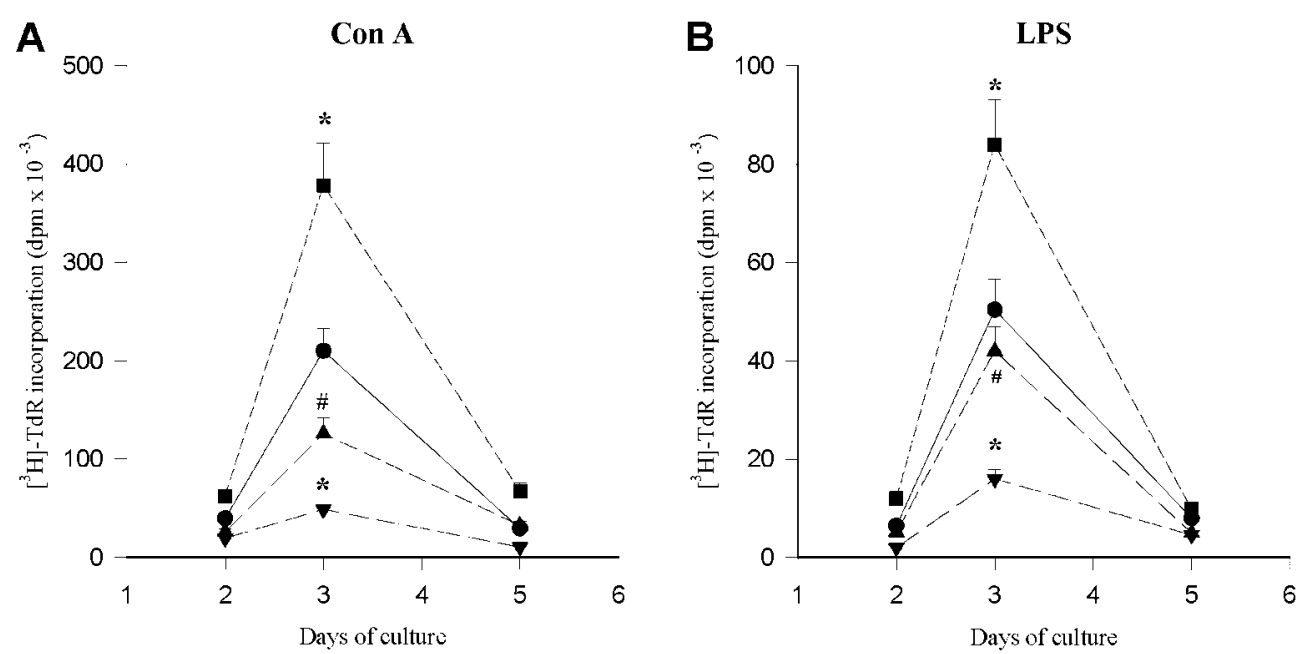

Figure 1 Effect of in vivo modulation of thyroid hormone levels on $\mathrm{T}$ and B lymphocyte proliferative activity. Lymph node or spleen cells were obtained from control (Normal, $\mathbf{O})$ or from animals treated with T4 ( $\mathbf{\square})$, PTU $(\boldsymbol{\nabla})$ or PTU+T3 $(\boldsymbol{\Delta})$. Cells $\left(1 \times 10^{6}\right.$ cells $\left./ \mathrm{ml}\right)$ were cultured in RPMI 1640 medium with $10 \%$ FCS and antibiotics in the absence or presence of the T- or B-selective mitogens (Con A ( $2 \mu \mathrm{g} / \mathrm{ml})$ or LPS (15 $\mu \mathrm{g} / \mathrm{ml})$ respectively) for the indicated times. Proliferation was evaluated by $\left[{ }^{3} \mathrm{H}\right] \mathrm{TdR}$ incorporation as indicated in Materials and Methods. Results shown are the mean d.p.m. values \pm S.E.M. of six experiments performed in triplicate.

\section{Measurement of cytokine levels}

Cytokine levels were determined in culture supernatants of phytohaemaggulinin (PHA)-stimulated lymph node cells from euthyroid, hyperthyroid or hypothyroid mice. Briefly, lymph node cells $\left(5 \times 10^{6}\right)$ were cultured as indicated above alone or in the presence of $25 \mu \mathrm{g} / \mathrm{ml}$ PHA for 24 or $48 \mathrm{~h}$. Supernatants were harvested and stored at $-80{ }^{\circ} \mathrm{C}$ before the assay was carried out. Cytokine levels in supernatants were measured by ELISA, according to the manufacturer's instructions (Pierce Endogen, Hercules, CA, USA). 3,3',5,5'-Tetramethylbenzidine was used to develop the color reaction. The absorbance was recorded at $450 \mathrm{~nm}$ by a microplate reader (model 550; BioRad). Cytokine concentrations were calculated based on a standard curve created using standard murine cytokines.

Cytokines released after immunization and in vitro re-stimulation of spleen cells from mice challenged with SRBCs were also measured. For this purpose mice were immunized with SRBCs $(0 \cdot 1 \mathrm{ml}$ of $2 \cdot 5 \%$ SRBCs intraperitoneally) and on the seventh day spleen cell suspensions were obtained, treated with $0 \cdot 83 \%$ ammonium chloride to lyse red blood cells, and cultured for 24 or $48 \mathrm{~h}$ in the absence or presence of $1 \%$ SRBCs in cultures. Supernatants were harvested and cytokine levels were determined as indicated previously.

Alternatively, animals were sensitized with LPS (one intraperitoneal injection of $20 \mu \mathrm{g}$ LPS per mouse, $1 \mathrm{mg} /$ $\mathrm{kg}$ ) as described before for developing inflammation (Xue et al. 2005). After 5 days, spleen cell suspensions were depleted of red blood cells and were restimulated in vitro with $1 \mu \mathrm{g} / \mathrm{ml}$ LPS for $24 \mathrm{~h}$. Cytokine levels were determined in cell-free supernatants of these cultures.

\section{Statistical analysis}

Student's $t$-test for unpaired values was used to determine the levels of significance. When multiple comparisons were necessary after ANOVA, Student-NewmanKeuls test was applied. Differences between means were considered significant if $P \leq 0 \cdot 05$.

\section{Results}

Mitogen-induced proliferative responses in lymphocytes from mice with differing thyroidal status

Selective mitogen-induced proliferative responses were studied in lymphocytes from euthyroid, hypothyroid and hyperthyroid mice. Figure 1 shows the time course of stimulation with Con A (Fig. 1A) or LPS (Fig. 1B), in lymph node and spleen lymphocytes respectively from animals with differing thyroid status. Hyperthyroid mice displayed higher $\left[{ }^{3} \mathrm{H}\right] \mathrm{TdR}$ incorporation, while hypothyroid mice displayed lower $\left[{ }^{3} \mathrm{H}\right] \mathrm{TdR}$ uptake, than control euthyroid animals. Reversion from hypothyroid state by T3 administration recovered proliferative responses reaching dpm values similar to those obtained in controls. As shown in Table 1, both T3 and T4 serum levels in these animals were higher in T4-treated animals and lower in PTU-treated animals, while levels of T3 hormone re- 
Table 1 HPT axis evaluation of euthyroid, hyperthyroid and hypo- and T3-treated hypothyroid mice

\begin{tabular}{|c|c|c|c|c|}
\hline & $\begin{array}{l}\mathbf{T 3}^{\mathbf{b}} \\
(\mathrm{ng} \%)\end{array}$ & $\begin{array}{l}\mathbf{T 4}^{\mathbf{b}} \\
(\mu \mathrm{g} \%)\end{array}$ & $\begin{array}{l}\mathbf{T S H}^{\mathbf{b}} \\
(\mathrm{ng} / \mathrm{ml})\end{array}$ & $\begin{array}{l}\mathbf{T R H}^{\mathbf{b}} \\
\text { (pg/mg protein) }\end{array}$ \\
\hline \multicolumn{5}{|l|}{ Treatment $^{a}$} \\
\hline Vehicle & $110 \pm 8$ & $4 \cdot 3 \pm 0 \cdot 3$ & $45 \pm 4$ & $625 \pm 50$ \\
\hline $\mathrm{T} 4$ & $347 \pm 43^{*}$ & $18 \cdot 4 \pm 1 \cdot 3^{*}$ & $<20$ & $309 \pm 38^{*}$ \\
\hline PTU & $62 \pm 4^{*}$ & $1 \cdot 1 \pm 0 \cdot 1^{*}$ & $61 \pm 4^{*}$ & $1348 \pm 132^{*}$ \\
\hline $\mathrm{PTU}+\mathrm{T} 3$ & $126 \pm 20^{\dagger}$ & $1 \cdot 2 \pm 0 \cdot 3^{*}$ & $40 \pm 5^{\dagger}$ & ND \\
\hline
\end{tabular}

\footnotetext{
a Mice ( $n=20$ in each group) were treated as indicated in Materials and Methods to obtain euthyroid (vehicle), hyperthyroid (T4), hypothyroid (PTU) or hypothyroid reverted with T3 (PTU + T3) conditions. ${ }^{\mathrm{b}}$ Serum thyroid hormone and TSH levels, and paraventricular TRH levels, were measured by RIA as indicated before; results shown are the mean \pm S.E.M. for each group.

*Differs significantly from the corresponding euthyroid mice with at least $P<0 \cdot 05$.

${ }^{\dagger}$ Differs from the corresponding PTU-treated mice with $P<0 \cdot 05$.
}

verted to normal values in T3-injected, PTU-treated mice. TSH serum levels were above basal values in hypothyroid mice, an effect that was reverted by T3 treatment, while almost undetectable TSH values were found in hyperthyroid animals. In addition, hypothalamic TRH levels were found to be increased in hypothyroid mice, but decreased in hyperthyroid mice, when compared with control animals.

From these results a clear relationship is demonstrated among thyroid hormone balance, with special reference to $\mathrm{T} 3$ serum levels and lymphocyte proliferation.

\section{Lymphocyte subsets and thyroid status}

To determine if the modulation of lymphocyte proliferation by thyroid status is related to differences in the lymphoid subset balance, lymphocyte subsets were analyzed by dual-flow cytometry using monoclonal antibodies specific for CD4 and CD8 markers. As shown in Fig. 2 and Table 2, no differences were found among $\mathrm{CD} 4^{+}, \mathrm{CD}^{+}$and dual-negative cells nor in the CD4/ CD8 ratio in lymphocytes from euthyroid, hyperthyroid, hypothyroid or PTU+T3-treated mice, thus indicating that differences in the lymphocyte proliferative pattern would be mainly related to cellular activation.

\section{Membrane PKC content and mitogen-induced translocation in lymphocytes from animals with differing thyroid status}

Since differences in proliferative responses could be due to modifications in intracellular signals, activation of PKC, one of the main enzymatic pathways involved in both $\mathrm{T}$ and $\mathrm{B}$ cell proliferation, was determined. As shown in Figs 3 and 4, both total PKC content, as well as mitogeninduced PKC translocation, were higher in $\mathrm{T}$ and $\mathrm{B}$ cells from hyperthyroid mice and lower in cells from hypothyroid mice, as compared with controls. Furthermore, T3 treatment of hypothyroid mice was able to reverse the PTUinduced effects on PKC content and membrane activity.
It is worth noting that PKC blockers, staurosporine and the more potent and specific inhibitor GF109203X, were able to inhibit mitogen-induced proliferation of both $\mathrm{T}$ and $\mathrm{B}$ cells (Table 3 ).

Cytokine levels in animals with differing thyroid status in response to antigen challenge or inflammatory stimulus

In order to further analyze the influence of thyroid hormone status in biologically relevant situations, such as
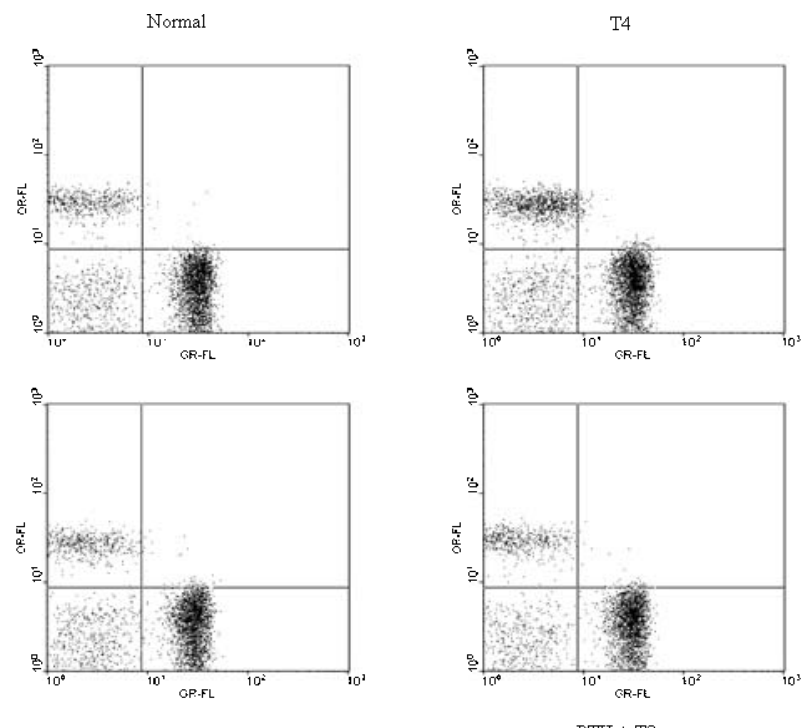

Figure 2 Surface expression of $\mathrm{CD}^{+}$and $\mathrm{CD}^{+}$on lymph node cells from normal, T4-, PTU- and PTU+T3-treated mice, as analysed by dual-wave flow cytometry. Cells $\left(1 \times 10^{6}\right)$ from normal, T4, PTU or PTU+T3 lymph nodes were labeled with both monoclonal anti-mouse CD4-FITC and CD8-R-PE-conjugated antibodies. Representative $(n=6)$ dot plots of two-color fluorescence analysis are shown. Dots representing cells carrying $\mathrm{CD}^{+}$marker only lie along the $y$-axis, while $\mathrm{CD}^{+}$cells lie along the $x$-axis. Between 8000 and 10000 events were analyzed per tube. 
Table $2 \mathrm{CD}^{+}$and $\mathrm{CD}^{+}$percentages, $\mathrm{CD} 4^{+} / \mathrm{CD}^{+}$ratios and percentage of double-negative in lymph nodes from normal (None), T4-, PTU- and PTU +T3-treated mice

\begin{tabular}{|c|c|c|c|c|}
\hline & $\mathrm{CD4}^{+} / \mathrm{CD8}^{+}$ & $\% \mathrm{CD}^{+}$ & $\% \mathrm{CD8}^{+}$ & $\mathrm{CD}^{-} / \mathrm{CD}^{-}$ \\
\hline \multicolumn{5}{|c|}{ Treatment } \\
\hline None & $2 \cdot 2 \pm 0 \cdot 3$ & $52 \cdot 2 \pm 3 \cdot 1$ & $24 \cdot 6 \pm 2 \cdot 0$ & $20 \cdot 8 \pm 2 \cdot 1$ \\
\hline T4 & $1 \cdot 8 \pm 0 \cdot 2$ & $49 \cdot 7 \pm 1 \cdot 5$ & $25 \cdot 7 \pm 1 \cdot 2$ & $22 \cdot 5 \pm 1 \cdot 8$ \\
\hline PTU & $2 \cdot 3 \pm 0 \cdot 3$ & $51 \cdot 3 \pm 3 \cdot 7$ & $23 \cdot 1 \pm 2 \cdot 6$ & $23 \cdot 1 \pm 3 \cdot 2$ \\
\hline PTU + T3 & $2 \cdot 6 \pm 0 \cdot 2$ & $55 \cdot 8 \pm 3 \cdot 5$ & $21 \cdot 1 \pm 0 \cdot 4$ & $20 \cdot 2 \pm 2 \cdot 8$ \\
\hline
\end{tabular}

Double-positive cells never exceeded $0 \cdot 5 \%$. Results are the mean \pm S.E.M. from six individual determinations. Non-statistically significant differences were found among groups by Student-Newman-Keuls test applied after ANOVA. It is worth noting that similar results were obtained on similar amounts of spleen cells from all experimental animal conditions.

antigen challenge or inflammation, key cytokine levels (namely IL-2, IFN- $\gamma$ and IL-6) were determined after in vivo administration of SRBCs or LPS and in vitro re-stimulation. As can be seen in Fig. 5, IL-2 and IFN- $\gamma$ release are increased in hyperthyroid lymphocytes while decreased in hypothyroid cells with respect to control after $\mathrm{T}$ cell-dependent antigen challenge with SRBC. However no differences were observed in IL-6 levels. Similar effects were obtained when stimulating $\mathrm{T}$ cells from non-immunized animals in vitro with PHA.

When animals were injected with the inflammatory dose of LPS, $80 \%$ of hyperthyroid mice died. Figure 5 depicts the cytokines levels in the remaining animals as well as those from control and hypothyroid mice after in vitro re-stimulation. No changes were found in IL-2 levels while increased release of IL-6 and IFN- $\gamma$ was observed only in hyperthyroid animals.

\section{Discussion}

Despite the important role assigned to thyroid hormones in maintaining immune system homeostasis (Foster et al. 2000, Dorshkind \& Horseman 2001), their participation in the regulation of the immune response is still controversial. In addition, a complete analysis of the HPT axis is lacking in those studies investigating the interaction between thyroid status and immunity. Furthermore, the modulation of intracellular signals in lymphocytes by in vivo fluctuations of thyroid hormones has not been previously studied. To clarify the role of the HPT axis in lymphocyte activity, experimental models of hyper- and hypothyroidism, as well as reversion of the PTU-induced hypothyroid state by T3 administration, were used and both thyroid axis and lymphocytes proliferation were evaluated. The biological significance of the thyroid axis
A

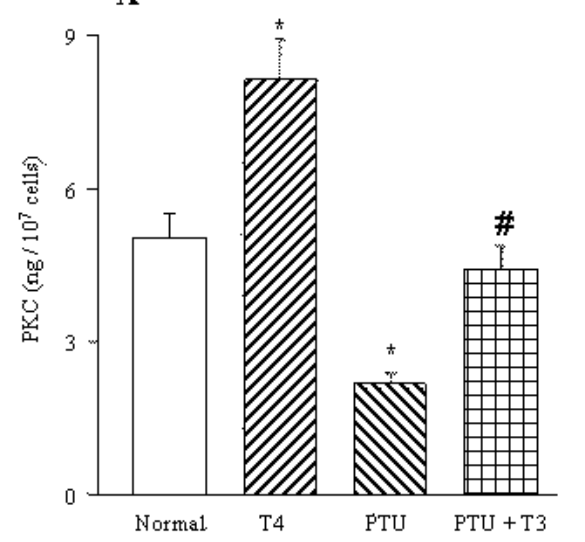

B

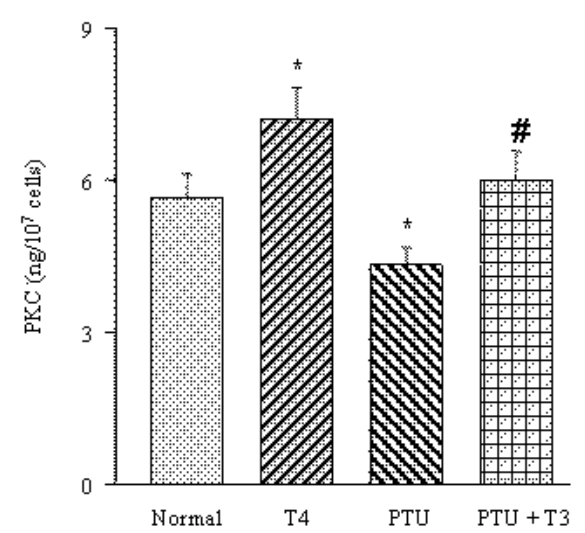

Figure 3 Total PKC content in B and T lymphocytes from animals with differing thyroid status. Total PKC was purified from $\mathrm{T}$ (A) or B (B) lymphocytes obtained from control (Normal) mice or from animals treated with T4, PTU or PTU+T3. PKC activity was measured as indicated and the content of PKC was calculated by interpolating the phosphorylation rate $(\mathrm{pmol} / \mathrm{min})$ of the samples in a dose-response curve obtained with PKC purified from rat brain. Results shown are the mean \pm S.E.M. of four experiments performed in duplicate. *Differs significantly from the corresponding normal values with at least $P<0 \cdot 05$. \#Differs significantly from the corresponding PTU values with at least $P<0 \cdot 05$. 

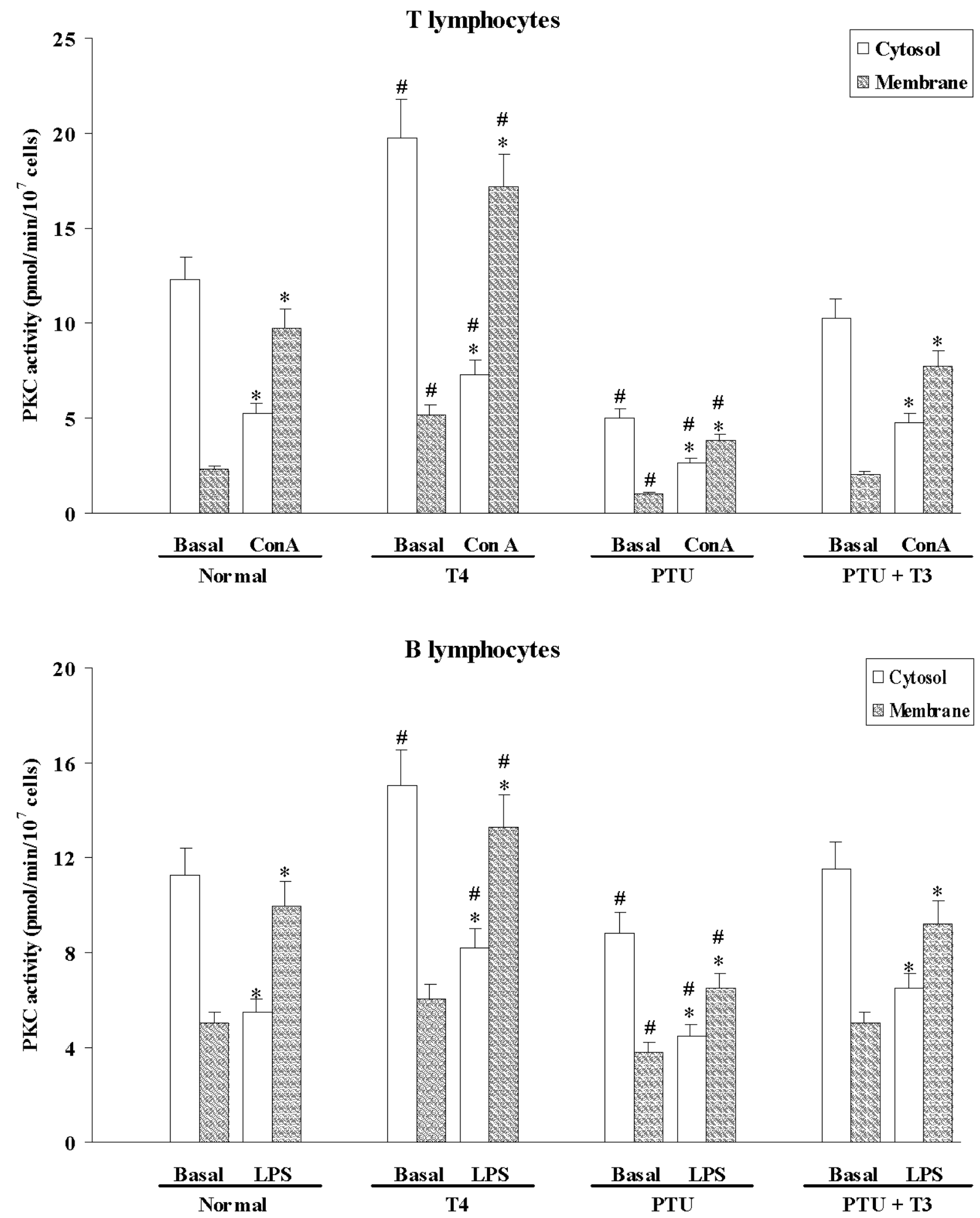

Figure 4 Differences in mitogen-induced PKC translocation to particulate fractions in lymphocytes from animals with differing thyroid status. PKC activity was purified from subcellular cytosol and membrane fractions from normal, T4-, PTU- or

PTU+T3-treated T or B lymphocytes assayed with histone $\mathrm{H}_{1}$ as substrate. Results shown are the mean \pm S.E.M. of three experiments performed in duplicate. ${ }^{*}$ Differs significantly from the corresponding basal values with $P<0 \cdot 01$; ${ }^{\#}$ Differs from the corresponding values of normal animals with at least $P<0 \cdot 05$. 
Table 3 Effect of PKC blockers on mitogen-induced proliferation of both T and B cells from normal, T4 or PTU mice

\begin{tabular}{|c|c|c|c|c|}
\hline & \multicolumn{4}{|c|}{ Proliferation (\% of control) ${ }^{a}$} \\
\hline & \multicolumn{2}{|c|}{ Staurosporine $(2 \mathrm{nM})$} & \multicolumn{2}{|c|}{ GF109203X $(1 \mu \mathrm{M})$} \\
\hline & T cells & B cells & T cells & B cells \\
\hline \multicolumn{5}{|l|}{ Treatment } \\
\hline None & $15 \pm 2$ & $20 \pm 3$ & $24 \pm 3$ & $28 \pm 4$ \\
\hline T4 & $22 \pm 3$ & $21 \pm 4$ & $31 \pm 3$ & $27 \pm 4$ \\
\hline PTU & $7 \pm 3$ & $11 \pm 2$ & $19 \pm 4$ & $20 \pm 3$ \\
\hline
\end{tabular}

${ }^{a}$ Cells were incubated with blockers and mitogens as indicated perviously and results are expressed as percentage of d.p.m. in mitogen-stimulated cultures without blocker. Results are the mean \pm S.E.M. of three experiments performed in triplicate.

modulation of lymphocyte function was also evaluated through the measurement of key cytokine release induced by antigen challenge.

Hypothryroid mice displayed both low serum levels of T3 and T4 and high serum TSH and hypothalamic TRH content, thus indicating that the duration and dose of PTU treatment used were appropriate for evaluating the action of low thyroidal status on immunity. It is worth noting that this dose of PTU is in the range of the minimum maintenance dose recently proposed for maintaining euthyroid status in Graves' disease (Kashiwai et al. 2003). In these conditions, lower proliferative responses to $\mathrm{T}$ - and $\mathrm{B}$-selective mitogens were found compared with euthyroid control mice. These results were not due to the immunosuppressive effects assigned to anti-thyroid drugs. In fact, PTU was demonstrated to interfere directly with mitogenic activation of lymphocytes only at drug concentrations that highly exceed those found in blood samples of patients treated for hyperthyroidism (Hallengren et al. 1980). In addition, the mechanism of their action was proposed to be indirect, through the diminished production of thyroid hormones (Volpe 2001). Reversion of PTU treatment with T3, increased T3 but not T4 levels, and decreased TSH to levels found in controls, an effect that was accompanied by a recovery in proliferative responses to both $\mathrm{T}$ - and $\mathrm{B}$-selective mitogens. It is worth noting that T3 reversion of anti-thyroid PTU treatment has been demonstrated to maintain low levels of T4 by other authors using similar drug administration schedules (Nishida \& Kawada 1992, Weiss et al. 1999), thus indicating that $\mathrm{T} 3$ is the thyroid hormone responsible for regulating lymphocyte activity. On the other hand, hyperthyroid mice showed high serum levels of T3 and $\mathrm{T} 4$, with undetectable levels of TSH, low levels of TRH and higher proliferative responses than controls. Nonstatistically significant differences in the kinetic course of $\mathrm{T}$ and $\mathrm{B}$ cell responses were found among groups.

In accordance with our results, a decrease in the proliferative responses to either T cell (Con A and PHA) or B cell (pokeweed mitogen (PWM)) mitogens in splenic
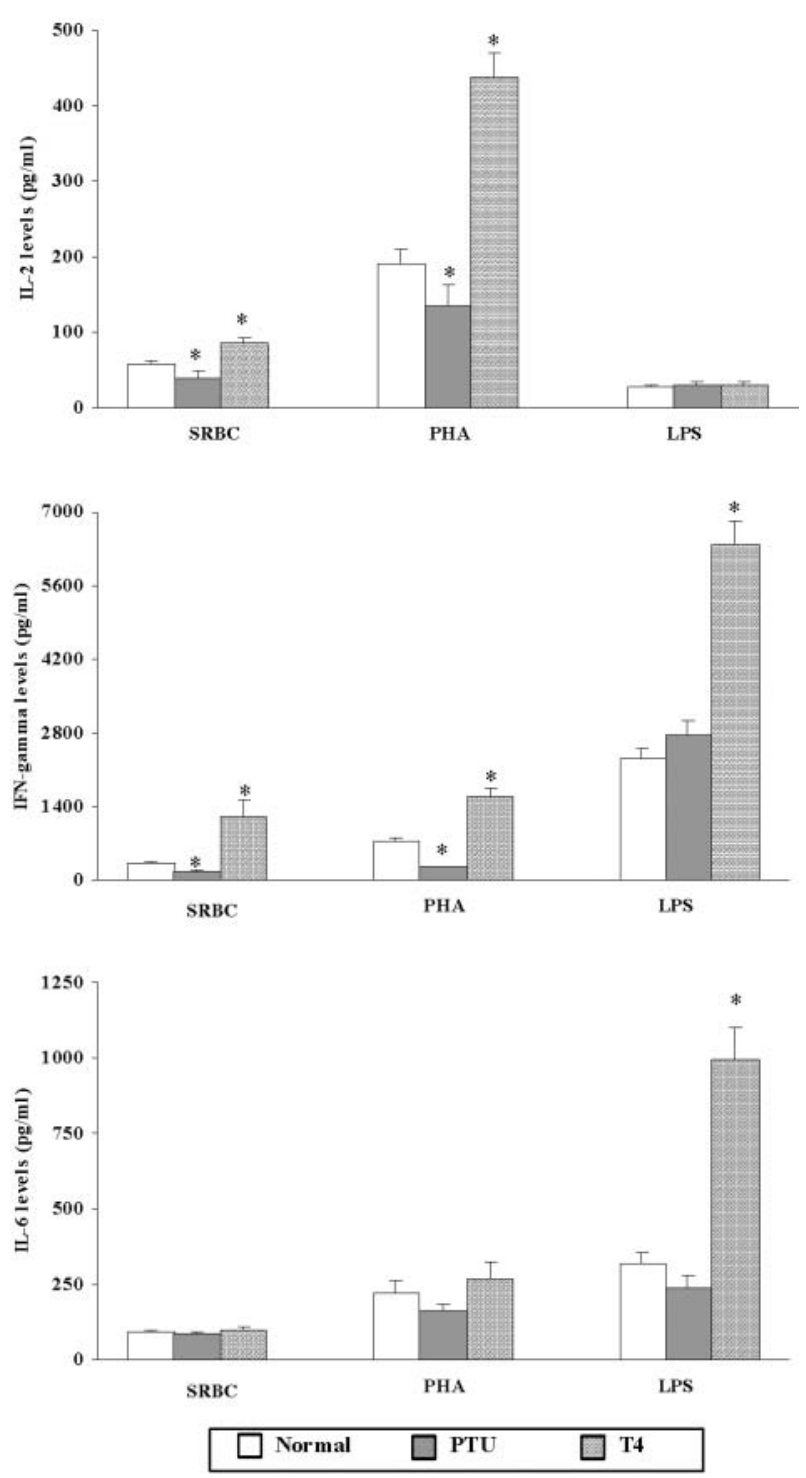

Figure 5 Cytokine levels from normal, hypothyroid (PTU) and hyperthyroid (T4) cells after antigenic challenge. IL-2, IFN- $\gamma$ and IL-6 levels were measured in cell-free supernatants from spleen cells after re-stimulation in vitro with SRBCs or LPS, or lymph node cells after PHA stimulation as described in Materials and Methods. Results shown are the mean \pm S.E.M. values of at least five animals of each experimental group. *Differs significantly from normal animals with at least $P<0 \cdot 05$.

and peripheral blood lymphocytes from hypothyroid animals (Chatterjee \& Chandel 1983, Fabris et al. 1995) has been previously reported. Furthermore, T3 administration was found to restore lymphocyte blastogenic responses in thyroidectomized rats (Chatterjee \& Chandel 1983). In addition, negative or positive modulation of cellular alloimmune responses was described in hypo- or hyperthyroid mice respectively (Klecha et al. 2000). Blastogenic responses to $\mathrm{T}$ and $\mathrm{B}$ cell mitogens were also found to be 
increased following T3 or T4 administration (Chatterjee \& Chandel 1983), with the $\mathrm{T}$ mitogenic response being significant after 1 month of treatment, similar to the duration of $\mathrm{T} 4$ administration in our study.

TSH has been shown to have a variety of immuneregulating cytokine-like activities that can affect the magnitude of antibody and cell-mediated responses of peripheral lymphocytes (Wang \& Klein 2001, Klein 2003). In fact, a TSH-mediated up-regulation of the mouse lymphocyte proliferative response to both Con A and PHA has been reported (Provinciali et al. 1992). With respect to TRH, it was suggested that this hormone exerts both direct and indirect effects on the immune system. Acute and chronic administration of TRH enhances the proliferation of splenic and thymic lymphocytes in rats (Winczyk \& Pawlikowski 2000). Finally, TRH administration in humans led to increased secretion of IL-2 into the blood (Komorowski et al. 1994). Although in vitro findings allow us to conclude that TSH and TRH enhance lymphocyte activity, the major concern with in vivo studies is to know whether their effects on immune responses are direct or are related to their regulation of the secretion of thyroid hormones. Our results for enhanced lymphoid responses, achieved with high levels of T3 and T4, but low levels of TSH and TRH - and with the converse in hypothyroid conditions - strengthened the possibility that levels of thyroid hormones modulate lymphocyte reactivity independently of TSH and TRH levels.

Changes in $\mathrm{T}$ helper/inducer $\left(\mathrm{CD} 4^{+}\right)$and $\mathrm{T}$ cytotoxic $\left(\mathrm{CD}^{+}\right)$cells are related to some pathologies that have alteration in both immune function and thyroid hormone levels - such as Down's syndrome, depression, and immune and non-immune thyroid diseases (Licastro et al. 2001, Bossowski et al. 2003). Therefore, we determined CD4/CD8 ratios in animals with differing thyroid status. Our results indicate that there were no significant variations in $\mathrm{CD}^{+}$and $\mathrm{CD}^{+}$cell counts in lymphoid compartments among euthyroid, hyperthyroid, hypothyroid or PTU+T3-treated animals. Similar results were found in children with non-immune thyroid disease or in euthyroid autoimmune Graves' patients (Bossowski et al. 2003). An abnormal distribution of $B, T$ and $T$ cell subsets in immune thyroid disorders would be related to autoimmunity development. On other hand, changes in hypo- and hyperthyroid $\mathrm{T}$ or $\mathrm{B}$ lymphocyte proliferative responses would not be a consequence of modifications of lymphocyte subset distribution, but would rather be related to cellular activation.

Lymphocytes from hyperthyroid mice displayed an increase in both total PKC cellular levels and mitogeninduced PKC translocation. In contrast, a decrease in these parameters was observed in hypothyroid animals. PKC blockers, staurosporine and GF103209X inhibit mitogen-induced proliferation in lymphocytes from control, hypo- and hyperthyroid mice similarly, thus indicating the importance of this enzymatic pathway. These results show, for the first time, thyroid hormonemediated regulation of PKC content in lymphocytes, which could be involved in altered responsiveness to mitogen-induced stimulation of proliferative responses. In support of our results, thyroid hormone modulation of PKC activity has been demonstrated in non-lymphoid tissues (Meier et al. 1991, Shimoni 1999, Pantos et al. 2001, Wong et al. 2001) and would probably indicate a genomic up-regulation of enzyme expression and/or function induced by thyroid hormones in lymphoid cells (Yen 2001).

In order to ascertain the importance of thyroid hormone actions on lymphocyte activity, key cytokine levels were determined after antigen challenge. For this purpose we evaluated IL-2 (a crucial cytokine for lymphocyte proliferation and activation), IFN- $\gamma$ (a Th1 cytokine important for cellular immunity) and the proinflammatory Th2 IL-6 cytokine (involved in promoting specific immune responses). Cells from hyperthyroid mice responded to the T cell-dependent antigen SRBC and to PHA by increasing IL-2 and IFN- $\gamma$ secretion, while cells from hypothyroid mice responded by decreasing IL-2 and IFN- $\gamma$ secretion, compared with control euthyroid cells. No differences were found for IL-6 levels, thus indicating the modulation by thyroid status of important cytokines related to cellular immunity. When injected with an inflammatory dose of LPS, most (80\%) hyperthyroid mice, but not control or hypothyroid mice, died of disseminated intravascular coagulation and multi-organ dysfunction, as shown by anatomical observation of animals during autopsy (data not shown). This would probably mean that this dose of LPS induced an endotoxic shock in hyperthyroid mice. Furthermore, high levels of the proinflammatory IL-6 cytokine were found in these animals. Similar to our results, a decrease in IL-2 levels after Con A stimulation of spleen cells was found in hypothyroid mice (Liu et al. 1995). However, Karanikas et al. (2004) found no differences in cytokine pattern in the sera of patients with non-immune severe hypothyroidism. When these results are considered together, it seems that thyroid hormones do not affect basal cytokine production but would change lymphocyte reactivity against any immune stimuli. Data regarding cytokine patterns in hyperthyroid status come from experimental models of Graves' disease and are all related to the development of autoimmunity. There are no available data on cytokine measurements in non-immune hyperthyroidism. Finally, our results indicate the important role of thyroid hormones in regulating lymphocyte reactivity, thus reinforcing the fact that sustained suppression of hormone levels would have deleterious biological effects on the overall ability of the host to generate a strong immune response. Moreover, these results form the basis for future research, proposing the regulation of thyroid hormone levels in pathologies with immunological abnormalities. 


\section{Acknowledgements}

The authors wish to thank Mrs María Rosa Gonzalez Murano and Mrs Ana Inés Casella for their excellent technical assistance. The authors declare that there is no conflict of interest that would prejudice the impartiality of this scientific work.

\section{Funding}

This work was partially supported by a collaborative grant from Fundación Antorchas and grants from CONICET (PIP 02720), Universidad de Buenos Aires (UBACYT B041) and Agencia Nacional de Promocion Científica y Tecnológica (PICT 05-08719).

\section{References}

Ballardin M, Gemignani F, Bodei L, Mariani G, Ferdeghini M, Rossi AM, Migliore L \& Barale R 2002 Formation of micronuclei and of clastogenic factor(s) in patients receiving therapeutic doses of iodine-131. Mutation Research 514 77-85.

Bossowski A, Urban M \& Stasiak-Barmuta A 2003 Analysis of changes in the percentage of $\mathrm{B}(\mathrm{CD} 19)$ and $\mathrm{T}$ (CD3) lymphocytes, subsets CD4, CD8 and their memory (CD45RO), naive (CD45RA) T cells in children with immune and non-immune thyroid diseases. Journal of Pediatric Endocrinology and Metabolism 16 63-70.

Cazaux CA, Sterin-Borda L, Gorelik G \& Cremaschi G 1995 Down-regulation of $\beta$ adrenergic receptors induced by mitogen activation of intracellular signaling events in lymphocytes. FEBS Letters 364 120-124.

Chatterjee S \& Chandel AS 1983 Immunomodulatory role of thyroid hormones: in vivo effect of thyroid hormones on the blastogenic response to lymphoid tissue. Acta Endocrinologica 103 95-100.

Davis SL 1998 Environmental modulation of the immune system via the endocrine system. Domestic Animal Endocrinology 15 283-289.

Dorshkind K \& Horseman ND 2000 The roles of prolactin, growth hormone, insulin-like growth factor-I, and thyroid hormones in lymphocyte development and function: insights from genetic models of hormone and hormone receptor deficiency. Endocrine Reviews 21 292-312.

Dorshkind K \& Horseman ND 2001 Anterior pituitary hormones, stress, and immune system homeostasis. Bioessays 23 288-294.

Fabris N, Mocchegiani E \& Provinciali M 1995 Pituitary-thyroid axis and immune system: a reciprocal neuroendocrine-immune interaction. Hormone Research 43 29-38.

Foster MP, Jensen ER, Montecino-Rodriguez E, Leathers H, Horseman N \& Dorshkind K 2000 Humoral and cell-mediated immunity in mice with genetic deficiencies of prolactin, growth hormone, insulin-like growth factor-I, and thyroid hormone. Clinical Immunology 96 140-149.

García SI, Dabsys SM, Santajuliana DO, Delorenzi A, Finkielman S, Nahmod VE \& Pirola CJ 1992 Interaction between thyrotropin-releasing hormone and the muscarinic cholinergic system in rat brain. Journal of Endocrinology 134 215-219.

Gorelik G, Barreiro Arcos ML, Klecha AJ \& Cremaschi GA 2002 Differential expression of protein kinase $\mathrm{C}$ isoenzymes related to high nitric oxide synthase activity in a T lymphoma cell line. Biochimica et Biophysica Acta 1588 179-188.
Hallengren B, Forsgren A \& Melander A 1980 Effects of anti-thyroid drugs on lymphocyte function in vitro. Journal of Clinical Endocrinology and Metabolism 51 298-301.

Karanikas G, John P, Wahl K, Schuetz M, Dudczak R \& Willheim M 2004 T-lymphocyte cytokine production patterns in nonimmune severe hypothyroid state and after thyroid hormone replacement therapy. Thyroid 14 488-492.

Kashiwai T, Hidaka Y, Takano T, Tatsumi KI, Izumi Y, Shimaoka Y, Tada H, Takeoka K \& Amino N 2003 Practical treatment with minimum maintenance dose of anti-thyroid drugs for prediction of remission in Graves' disease. Endocrine Journal 50 45-49.

Keast D \& Ayre DJ 1980 Antibody regulation in birds by thyroid hormone. Developmental and Comparative Immunology 4 323-330.

Klecha AJ, Genaro AM, Lysionek AE, Caro RA, Coluccia GA \& Cremaschi GA 2000 Experimental evidence pointing to the bidirectional interaction between the immune system and the thyroid axis. International Journal of Immunopharmacology 22 491-500.

Klein JR 2003 Physiological relevance of thyroid stimulating hormone and thyroid stimulating hormone receptor in tissues other than the thyroid. Autoimmunity 36 417-421.

Komorowski J, Stepien H \& Pawlikowski M 1994 Increased interleukin-2 levels during standard TRH test in man. Neuropeptides 27 151-156.

Licastro F, Mariani RA, Faldella G, Carpene E, Guidicini G, Rangoni Grilli T \& Bazzocchi G 2001 Immune-endocrine status and coeliac disease in children with Down's syndrome: relationship with zinc and cognitive efficiency. Brain Research Bulletin 55 313-317.

Liu WK, Tsui KW, Lai KW \& Xie Y 1995 Sister-chromatid exchanges in lymphocytes from methimazole-induced hypothyroid mice. Mutation Research 326 193-197.

Meier CA, Fabbro D, Meyhack I, Hemmings B, Olbrecht U, Jakob A \& Walter P 1991 Effect of hypothyroidism and thyroid hormone replacement on the level of protein kinase $\mathrm{C}$ and protein kinase $\mathrm{A}$ in rat liver. FEBS Letters 282 397-400.

Nishida M \& Kawada J 1992 Hormonal control of manganese transport in the mouse thyroid. Experientia 48 262-265.

Ohashi H \& Itoh M 1994 Effects of thyroid hormones on lymphocyte phenotypes in rats: changes in lymphocyte subsets related to thyroid function. Endocrine Regulations 28 117-123.

Pantos CI, Malliopoulou VA, Mourouzis IS, Karamanoli EP, Tzeis SM, Carageorgiou HC, Varonos DD \& Cokkinos DV 2001. Long-term thyroxine administration increases heat stress protein-70 mRNA expression and attenuates p38 MAP kinase activity in response to ischaemia. Journal of Endocrinology 170 207-215.

Pawlikowski M, Stepien H \& Komorowski J 1994 Hypothalamic-pituitary-thyroid axis and the immune system. Neuroimmunomodulation 1 149-152.

Provinciali M, Di Stefano G \& Fabris N 1992 Improvement in the proliferative capacity and natural killer cell activity of murine spleen lymphocytes by thyrotropin. International Journal of Immunopharmacology 14 865-870.

Schoenfeld PS, Myers JW, Myers L \& LaRocque JC 1995 Suppression of cell-mediated immunity in hypothyroidism. Southern Medical Journal 88 347-349.

Shimoni Y 1999 Protein kinase C regulation of $\mathrm{K}^{+}$currents in rat ventricular myocytes and its modification by hormonal status. Journal of Physiology $\mathbf{5 2 0}$ 439-449.

Shinohara R, Mano T, Nagasaka A, Hayashi R, Uchimura K, Nakano I, Watanabe F, Tsugawa T, Makino M, Kakizawa $\mathrm{H}$ et al. 2000 Lipid peroxidation levels in rat cardiac muscle are affected by age and thyroid status. Journal of Endocrinology 164 97-102.

Streetman DD \& Khanderia U 2003 Diagnosis and treatment of Graves disease. Annals of Pharmacotherapy 37 1100-1109.

Volpe R 2001 The immunomodulatory effects of anti-thyroid drugs are mediated via actions on thyroid cells, affecting thyrocyte-immunocyte signalling: a review. Current Pharmaceutical Design 7 451-460. 
Wang H-C \& Klein JR 2001 Immune function of thyroid stimulating hormone and receptor. Critical Reviews in Immunology 21 323-337.

Weiss RE, Xu J, Ning G, Pohlenz J, O’Malley BW \& Refetoff S 1999 Mice deficient in the steroid receptor co-activator 1 (SRC-1) are resistant to thyroid hormone. EMBO Journal 18 1900-1904.

Winczyk K \& Pawlikowski M 2000 Time of day-dependent effects of thyroliberin and thyrotropin on thymocyte proliferation in rats. Neuroimmunomodulation 7 89-91.

Wong YK, Tang KT, Wu JC, Hwang JJ \& Wang HS 2001 Stimulation of hyaluronan synthesis by interleukin-1 beta involves activation of protein kinase C beta II in fibroblasts from patients with Graves' ophthalmopathy. Journal of Cellular Biochemistry 82 58-67.
Xue X, Lai KT, Huang JF, Gu Y, Karlsson L \& Fourie A 2005 Anti-inflammatory activity in vitro and in vivo of the protein farnesyltransferase inhibitor, tipifarnib. Journal of Pharmacology and Experimental Therapeutics (in press).

Yen PM 2001 Physiological and molecular basis of thyroid hormone action. Physiological Reviews 81 1097-1141.

Received in final form 22 December 2005 Accepted 19 January 2006 